\title{
Coagulase production by strains of Staphylococcus aureus of differing resistance characters: a comparison of two traditional methods with a latex agglutination system detecting both clumping factor and protein $\mathrm{A}$
}

\author{
JANET IS DICKSON, RR MARPLES \\ From the Division of Hospital Infection, Central Public Health, Laboratory, Colindale, London
}

SUMMARY Five groups of strains of Staphylococcus aureus (54 in total) were tested by slide and tube coagulase methods with rabbit and human plasma, and the results were compared with a latex test for both clumping factor and Protein A (Staphaurex, Wellcome Foundation). The five groups comprised: epidemic methicillin resistant $S$ aureus (group 1); other methicillin resistant $S$ aureus (group 2); other resistant $S$ aureus (group 3); other $S$ aureus (group 4); and a group of reference strains, not all true $S$ aureus (group 5).

Groups 1, 3, and 4 gave consistently strong positive results with the tube test and the latex test and less strong positive results with the slide test. Group 2 strains sometimes gave weak or negative results in slide and latex tests, but tube tests with both types of plasma were strongly positive. Only within group 5 strains were negative results in the tube test found. Group 1 strains showed no diminution in expression of free coagulase or of clumping factor. The latex test was more sensitive than the slide test but less sensitive than the tube test. Doubtful or negative slide test or latex test results, particularly with strains resistant to methicillin, should be checked by a tube coagulase test.

The tube coagulase test with diluted rabbit plasma is the accepted confirmation of an identification of Staphylococcus aureus, ${ }^{1}$ but either a tube test with human plasma broth or some variant of the slide clumping factor (bound coagulase) test is more often used at the bench. With most human strains there is no difficulty, but it has been suggested that strains of $S$ aureus, which are resistant to methicillin, are deficient in clumping factor and even in Protein A. Lally and Woolfrey ${ }^{2}$ found that some strains of $S$ aureus resistant to methicillin may be particularly deficient, and similar findings were reported at a workshop on the problems caused by some strains resistant to this drug. ${ }^{3}$ Other characters such as DNAase production, phosphatase, and ability to acidify mannitol salt agar have been used with varying efficacy to confirm or suggest an identification of a strain as $S$ aureus.

A new latex agglutination system (Staphaurex, Wellcome Foundation) in which the polystyrene latex particles are coated with fibrinogen and IgG has recently been introduced. When mixed on a slide, or on the card supplied, a suspension of $S$ aureus cells shows

Accepted for publication 4 December 1985 coagglutination with the latex particles either by the action of clumping factor with the fibrinogen or by the action of Protein A on the Fc segment of the IgG, or by both. The opportunity to review bench techniques for the confirmation of $S$ aureus isolations was combined with a study of the characteristics of methicillin resistant $S$ aureus, an epidemic methicillin resistant strain, and of other currently circulating resistant and sensitive clinical strains, as well as a series of reference strains.

The species group previously included within $S$ aureus was divided by various characters into biotypes by Hajek and Marsalek. ${ }^{4}$ Essentially, each biotype was restricted to a narrow range of host species, with biotype $\mathrm{A}$ including most human strains, biotype $\mathrm{C}$ including strains from bovine sources, and the other biotypes from other animal sources. Biotypes $E$ and $F$ from dogs and some other animals have recently been accepted as a new species, $S$ intermedius. ${ }^{5}$ The relation between this species and isolates classified as Mycrobacterium hyicus or S III in the Baird-Parker system $^{6}$ is not yet clear. Strains of $S$ aureus from human sources are usually positive in coagulase tests using human or rabbit plasma, while $S$ intermedius 
and $S$ hyicus strains react with rabbit plasma but not with human plasma. Strains identified as S III are said to be coagulase negative. Protein $A$ is restricted to the human biotype of $S$ aureus and should permit reactions with the sensitised latex particles, even if human strains are deficient in clumping factor.

A collection of 54 strains of $S$ aureus, selected initially for tests of sensitivity to antibacterial agents, was available for study. The strains were chosen to represent the range of the strain epidemic in the Thames health regions resistant to methicillin (group 1), other methicillin resistant $S$ aureus (group 2), multiresistant but methicillin sensitive strains (group 3), relatively sensitive strains (group 4) representative of strains found in the British Isles ${ }^{3}$ and a control group (group 5) of reference strains, laboratory constructs, and animal strains including three strains identified as $S$ intermedius.

The possibility of resolving in one study two separate questions both of which were topical and important was inviting. The best test of a new product is a controversial question. We therefore investigated a relatively small number of highly selected strains by the traditional methods of eliciting the coagulase reaction and compared the results with a latex test for bound coagulase and Protein A.

\section{Material and methods}

SOURCE OF STRAINS

The strains in the first four groups were selected from specimens tested routinely by the Staphylococcus Reference Laboratory in the period June to August 1984 and, except for strains from group 1, which were restricted to the Thames regions, were balanced in geographical location within Great Britain. Two control non-epidemic methicillin resistant strains (CRF 612 , a methicillin resistant strain from a collection held by the Division of Hospital Infection, CPHL ${ }^{7}$, numbered with the prefix CRF and NCTC 10442) were included as group 2 strains.

The strains in the fifth group were all derived from

Table 1 Composition of the miscellaneous group (group 5)

\begin{tabular}{|c|c|c|}
\hline$C R F$ & NCTC & Source \\
\hline \multirow{4}{*}{$\begin{array}{r}77 \\
89 \\
166 \\
188 \\
234\end{array}$} & & \multirow{9}{*}{$\begin{array}{l}\text { Nurse's uniform } \\
\text { Pig } \\
\text { Heatley (Oxford) } \\
\text { Deer } \\
\text { Laboratory derivative of NCTC7121 } \\
\text { clumping factor positive } \\
\text { Laboratory derivative of NCTC7121 } \\
\text { clumping factor negative } \\
\text { Cow } \\
\text { Chicken } \\
\text { Dog }(S \text { intermedius }) \\
\text { Dog }(S \text { intermedius }) \\
\text { Dog }(S \text { intermedius })\end{array}$} \\
\hline & 6571 & \\
\hline & & \\
\hline & 10344 & \\
\hline 235 & 10345 & \\
\hline $\begin{array}{l}285 \\
344\end{array}$ & & \\
\hline $\begin{array}{l}344 \\
394\end{array}$ & & \\
\hline 413 & & \\
\hline 426 & & \\
\hline
\end{tabular}

the CRF collection and included four animal strains classifiable as $S$ aureus, subcultures of NCTC6512 (Oxford), and other reference strains (Table 1).

\section{THE LATEX TEST}

This test was carried out according to the directions supplied with the kit. Briefly, one drop of the shaken latex suspension was placed on the black circle on the card, and the growth from six colonies from an overnight culture at $37^{\circ} \mathrm{C}$ on nutrient agar was emulsified into the drop. A period of 10 seconds was allowed for emulsifying and spreading followed by 20 seconds gentle rotation before the final reading was made. To quantify the results in this study the manufacturer's recommendations for interpreting the reaction on the card were modified to create an arbitrary scoring system as follows: $(4+)$ the reaction begins within the first 10 seconds resulting in complete clearing of the milky background; $(3+)$ the reaction begins within the first 10 seconds resulting in incomplete clearing; $(2+)$ the reaction begins after the first 10 seconds resulting in incomplete clearing; $(1+)$ the reaction begins after the first 10 seconds resulting in very little clearing, (this would be considered a negative result according to the manufacturer's instructions); (negative) there is no agglutination or clearing observed.

\section{THE SLIDE COAGULASE TEST}

This test was performed using human and rabbit plasma diluted $1 / 10$ in nutient broth. Colonies from an overnight culture on nutrient agar plates incubated at $37^{\circ} \mathrm{C}$ were emulsified in one drop of saline, and one drop of plasma broth was added. Ten seconds were allowed for mixing followed by 20 seconds of rotation before the final reading. The reaction was scored in the same way as that used for the latex reaction.

\section{THE TUBE COAGULASE TEST}

This test was performed using $0 \cdot 2 \mathrm{ml}$ of an overnight culture of each organism in brain heart infusion broth added to $2 \mathrm{ml}$ of each of rabbit and human plasma nutrient broths, each being a $1 / 10$ dilution of plasma, mixed, and incubated at $37^{\circ} \mathrm{C}$. The tests were read after two, four, and 24 hours and scored as below: $(4+)$ the fibrin clot fills the complete volume occupied by the broth; $(3+)$ the clot fills more than half but less than the total volume occupied by the broth; $(2+)$ the clot fills less than half the total volume occupied by the broth; $(1+)$ there is a little disorganised clot formation; (negative) no clot observed but a little amorphous deposit might be seen.

After 24 hours some clot structure was lost, and this was recorded as a shrinkage. This may have been due to disturbance of the tubes in taking earlier readings or to the activity of bacterial proteases. All of the tests were carried out in duplicate. 


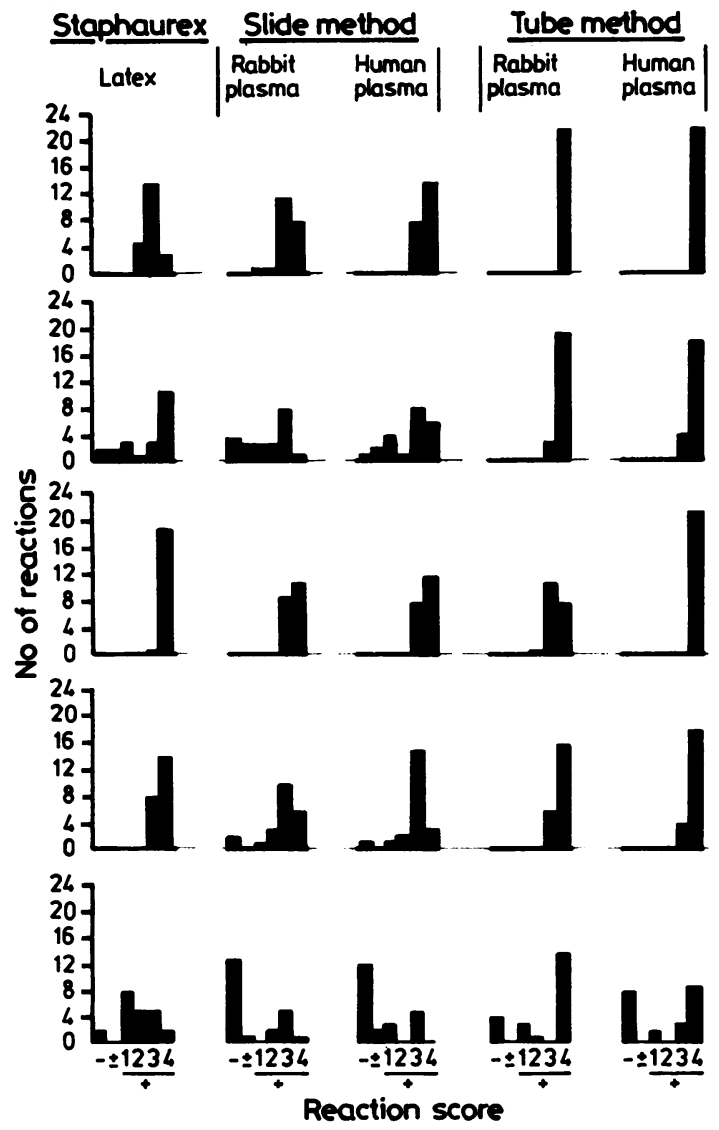

Incidence of reaction scores observed for different groups of strains tested in duplicate with Staphaurex and slide and tube coagulase tests.

\section{Results}

The Figure charts the number of responses in duplicated tests in each group of strains at each strength according to the grading defined above. Only four pairs of results showed a discrepancy of more than one grade. All occurred in the rabbit plasma slide test and included three group 2 strains and one group 4 strain. Three differed from negative to $2+$ and one, a group 2 strain, from $1+$ to $3+$. Table 2 shows the average results.

Strains identified as group 1 gave maximal responses in both tube tests and repeatedly gave strong to maximal reactions in slide tests with human plasma. Reactions in the latex test were less than maximal in only three of 22 trials. One strain, 84/5207, gave low scores in the rabbit plasma slide test of $1+$ and $2+$. This strain was originally identified as group 1 but may be group 2 strain, as its protein profile differs from other group 1 strains (S Tabaqchali personal communication). If this strain is excluded the average score for the rabbit plasma slide test for this group rises to 3.4 and for the human plasma test to 3.7. The latex test results were unchanged.

Table 3 lists the results for group 2 strains. Strains $84 / 6077,6255$, and 6582 repeatedly gave low scores in both the latex and slide tests but high scores in the tube tests as did the control strains CRF612 and NCTC10442. Strains 6145 and 7031 scored higher in the slide test with human plasma than with rabbit plasma but reacted strongly in latex and tube tests.

The strains in group 5 showed the expected wide range of results because of the selection of aberrant or constructed strains (Table 4). Strain CRF77, originally derived from a nurse's uniform, is unusual in showing greater clumping factor activity than tube coagulase activity. This was confirmed in the present study. The superiority of the rabbit plasma tube test for eliciting the coagulase character in $S$ intermedius (strains CRF394, 413, and 426) and in the bovine CRF285 was evident. The latex test paralleled the tube test but with lower sensitivity. Indeed, according to the manufacturer's instructions, $S$ intermedius strains would be identified as coagulase negative.

\section{Discussion}

When $S$ aureus is suspected most hospital microbiologists usually perform a simple confirmatory test at the bench. The tube coagulase test is accepted as the definitive test, particularly in medical microbiology, but the advantages of the slide test for clumping factor in terms of speed and simplicity often make this the preferred test. Recognising methicillin

Table 2 Average score attained in each group for different methods of testing

\begin{tabular}{|c|c|c|c|c|c|}
\hline & \multirow{2}{*}{$\begin{array}{l}\text { Latex } \\
\text { coagglutination }\end{array}$} & \multicolumn{2}{|l|}{ Slide } & \multicolumn{2}{|l|}{ Tube } \\
\hline & & Rabbit & Human & Rabbit & Human \\
\hline $\begin{array}{l}\text { Group } 1(\mathrm{n}=22) \\
\text { Group } 2(\mathrm{n}=22) \\
\text { Group } 3(\mathrm{n}=20) \\
\text { Group } 4(\mathrm{n}=22) \\
\text { Group } 5(\mathrm{n}=22)\end{array}$ & $\begin{array}{l}2.91 \\
3.14 \\
3.95 \\
3.64 \\
1.86\end{array}$ & $\begin{array}{l}3.23 \\
1.75 \\
3.75 \\
2.77 \\
1.07\end{array}$ & $\begin{array}{l}3.64 \\
2.50 \\
3.60 \\
2.82 \\
0.86\end{array}$ & $\begin{array}{l}4 \cdot 0 \\
3 \cdot 86 \\
3 \cdot 35 \\
3 \cdot 68 \\
2 \cdot 77\end{array}$ & $\begin{array}{l}4 \cdot 0 \\
3 \cdot 82 \\
4 \cdot 0 \\
3 \cdot 82 \\
2 \cdot 14\end{array}$ \\
\hline
\end{tabular}


Table 3 Detailed results for strains identified as other methicillin resistant $S$ aureus (group 2)

\begin{tabular}{|c|c|c|c|c|c|c|c|c|c|c|}
\hline \multirow{2}{*}{$\begin{array}{l}\text { Strain } \\
\text { No 84/ } \\
6077\end{array}$} & \multirow{2}{*}{\multicolumn{2}{|c|}{$\begin{array}{l}\text { Latex } \\
\text { coagglutination }\end{array}$}} & \multicolumn{4}{|c|}{ Slide method } & \multicolumn{4}{|c|}{ Tube method } \\
\hline & & & \multicolumn{2}{|c|}{ Rabbit plasma } & \multicolumn{2}{|c|}{ Human plasma } & \multicolumn{2}{|c|}{ Rabbit plasma } & \multicolumn{2}{|c|}{ Human plasma } \\
\hline $\begin{array}{l}6077 \\
6144 \\
6145 \\
6255 \\
6582 \\
6621 \\
6983 \\
7031 \\
7046 \\
\text { CRF612 } \\
\text { NCTC10442 }\end{array}$ & $\begin{array}{l}- \\
4+ \\
4+ \\
2+ \\
+1- \\
4+ \\
4+ \\
4+ \\
4+ \\
1+ \\
3+\end{array}$ & $\begin{array}{l}- \\
3+ \\
4+ \\
1+ \\
+1- \\
4+ \\
4+ \\
4+ \\
4+ \\
1+ \\
3+\end{array}$ & $\begin{array}{l}+1- \\
3+ \\
-1+ \\
+1- \\
3+ \\
3+ \\
1+ \\
3+ \\
-\end{array}$ & $\begin{array}{l}+1- \\
3+ \\
2+ \\
2+ \\
1+ \\
3+ \\
3+ \\
3+ \\
4+ \\
\frac{2+}{4}\end{array}$ & $\begin{array}{l}- \\
3+ \\
3+ \\
3+ \\
+1- \\
3+ \\
3+ \\
3+ \\
4+ \\
1+ \\
1+\end{array}$ & $\begin{array}{l}+1- \\
4+ \\
4+ \\
3+ \\
1+ \\
3+ \\
4+ \\
4+ \\
4+ \\
1+ \\
2+\end{array}$ & $\begin{array}{l}4 t \\
4 t \\
4 t \\
4 t \\
4 t \\
4 t \\
4 t \\
4 t \\
4 t \\
3 t \\
4 t\end{array}$ & $\begin{array}{l}4+ \\
4+ \\
4+ \\
4+ \\
4+ \\
4+ \\
4+ \\
3+ \\
4+ \\
3+ \\
4+\end{array}$ & $\begin{array}{l}4+ \\
4+ \\
4 t \\
4 t \\
3+ \\
4+ \\
4+ \\
4+ \\
4+ \\
3+ \\
4+\end{array}$ & $\begin{array}{l}4+ \\
4+ \\
4+ \\
4+ \\
3+ \\
4+ \\
4+ \\
4+ \\
4+ \\
3+ \\
4+\end{array}$ \\
\hline
\end{tabular}

Table 4 Detailed results for group of miscellaneous strains (group 5)

\begin{tabular}{|c|c|c|c|c|c|c|c|c|c|c|}
\hline \multirow{2}{*}{$\begin{array}{l}\text { CRF No } \\
77\end{array}$} & \multirow{2}{*}{\multicolumn{2}{|c|}{$\begin{array}{l}\text { Latex } \\
\text { coagglutination }\end{array}$}} & \multicolumn{4}{|c|}{ Slide method } & \multicolumn{4}{|c|}{ Tube method } \\
\hline & & & \multicolumn{2}{|c|}{ Rabbit plasma } & \multicolumn{2}{|c|}{ Human plasma } & \multicolumn{2}{|c|}{ Rabbit plasma } & \multicolumn{2}{|c|}{ Human plasma } \\
\hline $\begin{array}{r}77 \\
89 \\
166 \\
188 \\
234 \\
235 \\
285 \\
344 \\
394 \\
413 \\
426\end{array}$ & $\begin{array}{l}3+ \\
3+ \\
2+ \\
2+ \\
1+ \\
3+ \\
3+ \\
1+ \\
1+ \\
1+\end{array}$ & $\begin{array}{l}4+ \\
2+ \\
2+ \\
3+ \\
1+ \\
2+ \\
4+ \\
1+ \\
1+ \\
1+\end{array}$ & $\begin{array}{l}3+ \\
+1- \\
2+ \\
= \\
= \\
3+ \\
2+ \\
=\end{array}$ & $\begin{array}{l}4+ \\
\frac{4}{3+} \\
= \\
= \\
3+ \\
3+ \\
=\end{array}$ & $\begin{array}{l}3+ \\
1+ \\
1+ \\
3+ \\
= \\
+1- \\
1+ \\
= \\
=\end{array}$ & $\begin{array}{l}3+ \\
\overline{-} \\
= \\
= \\
+1- \\
= \\
=\end{array}$ & $\begin{array}{l}\overrightarrow{4+} \\
4+ \\
4+ \\
4+ \\
\overline{4+} \\
4+ \\
1+ \\
4+ \\
2+\end{array}$ & $\begin{array}{l}-\overline{4+} \\
4+ \\
4+ \\
4+ \\
\overline{4+} \\
4+ \\
1+ \\
4+ \\
1+\end{array}$ & $\begin{array}{l}1+ \\
4+ \\
4+ \\
3+ \\
4+ \\
-3+ \\
4+ \\
= \\
-\end{array}$ & $\begin{array}{l}1+ \\
4+ \\
4+ \\
3+ \\
4+ \\
-4+ \\
4+ \\
= \\
-\end{array}$ \\
\hline
\end{tabular}

resistant $S$ aureus at the bench may currently cause difficulties, because so many coagulase negative staphylococci in hospitals display resistance to methicillin ${ }^{8}$ and because methicillin resistant $S$ aureus may fail to give a positive slide coagulase test, ${ }^{2}$ so an effective latex test might have a role. The results of this study show that no difficulties should arise with the strain of $S$ aureus presently epidemic in the Thames regions, which is methicillin resistant (group 1). Difficulties may arise with other methicillin resistant strains of $S$ aureus, some of which do seem to be deficient in clumping factor and some also deficient in protein A. Failures of confirmation because of autoagglutination or because the strain is of animal origin can usually be detected and a definitive test is then set up. The latex test, as the results presented show, is more sensitive than the slide test and may be valuable in the clincal laboratory as a bench test.

The wider problem of defining the limits of the species $S$ aureus is more difficult to answer. The clinical laboratory aims to identify human strains of $S$ aureus economically but not to miss infections with animal strains. The importance of $S$ intermedius and $S$ hyicus in human medicine is unclear but such strains will occur from time to time. Tests by the tube method with different plasmas still seem to be more reliable than the quick slide tests. The ancillary tests for phos- phatase, DNAase, and mannitol fermentation serve the function of screening mixed cultures for suspicious colonies. These are useful for human strains but may become misleading as the clinical laboratory extends its scope from isolates from disease to isolates from the normal flora of man and animals and to isolates from the environment.

In conclusion, this study of current strains shows that:

(1) The epidemic strain of methicillin resistant $S$ aureus prevalent in the Thames region shows no diminution in expression of coagulase but that some other methicillin resistant strains may do so.

(2) Tube methods are more sensitive than slide methods.

(3) Human plasma is as good if not better than rabbit plasma for human strains, but rabbit plasma is necessary for animal strains.

(4) The latex method showed greater sensitivity than the slide test and therefore may be helpful in a clinical laboratory.

\section{References}

${ }^{1}$ Cowan ST, Steel KG. Manual for the identification of medical bacteria. 2nd ed. Cambridge: Cambridge University Press, 1974.

${ }^{2}$ Lally R, Woolfrey B. Clumping factor defective MRSA. Eur J Clin Microbiol 1984;3:151-2. 
${ }^{3}$ Marples RR, Cooke EM. Report of a Workshop on methicillinresistant Staphylococcus aureus. J Hosp Infect 1985;6:342-8.

${ }^{4}$ Hajek V, Marsalek E. The differentiation of pathogenic staphylococci and a suggestion for their taxonomic classification. Zentralblatt fur Bakteriologie, Parasitenkunde, Infectionskrankheiten und Hygiene. Abteilung I Originale Reihe A 1971;217:176-82.

${ }^{5}$ Hajek V. Staphylococcus intermedius, a new species isolated from animals. Int J Syst Bacteriol 1976;26:401-8.

${ }^{6}$ Baird-Parker AC. A classification of micrococci and staphylococci based on physiological and biochemical tests. J Gen Microbiol
1963;30:409-27.

${ }^{7}$ McKay-Ferguson E. Organic acids in microbiology. University of London. (thesis).

${ }^{8}$ Richardson JF, Marples RR. Changing resistance to antimicrobial drugs, and resistance typing in clinically significant strains of Staphylococcus epidermidis. J Med Microbiol 1982;15:475-84.

Requests for reprints to: Miss Janet IS Dickson. Division of Hospital Infection, Central Public Health Laboratory, 61 Colindale Avenue, London NW9 5HT, England. 